\title{
Fuzzy modelling of acid mine drainage environments using geochemical, ecological and mineralogical indicators
}

\author{
T. MARia VAlente ${ }^{(1)}$; C. Leal Gomes ${ }^{(1)}$ \\ ${ }^{(1)}$ Centro de Investigação Geológica, Ordenamento e Valorização de Recursos (CIG-R) \\ - Universidade do Minho, Campus de Gualtar, 4710-057 Braga, Portugal
}

T. Maria Valente

EMail: teresav@dct.uminho.pt

\begin{abstract}
Fuzzy logic was applied to model acid mine drainage (AMD) and to obtain a classification index of the environmental impact in a contaminated riverine system. The data set used to develop this fuzzy model (a fuzzy classifier) concerns to an abandoned mine in Northern Portugal - Valdarcas mining site. Here, distinctive drainage environments (spatial patterns) can be observed based on the acid mine drainage formed in the sulphide-rich waste-dumps. Such environments were established, as the effluent flows through the mining area, using several kinds of indicators. These are physical-chemical, ecological and mineralogical parameters, being expressed in a quantitative or qualitative basis. The fuzzy classifier proposed in this paper is a min-max fuzzy inference system, representing the spatial behaviour of those indicators, using the AMD environments as patterns. As they represent different levels (classes) of contamination, the fuzzy classifier can be used as a tool, allowing a more reasonable approach, compared with classical models, to characterize the environmental impact caused by AMD.

In a general way it can be applied to other sites where sulphide-rich waste-dumps are promoting the pollution of superficial water through the generation of AMD.
\end{abstract}

Keywords (5): Acid mine drainage, fuzzy classifier, min-max fuzzy, environmental impact classification, Valdarcas - Portugal. 


\section{Introduction}

Acid mine drainage (AMD) that emerges from sulphide-rich waste-dumps is a peculiar focus of environmental impact in aquatic systems. It is recognized as a complex multifactor pollutant, which promotes chemical, physical, biological and ecological interactive effects on the ecosystems (Gray 1998). To better understand its origin, as well as to describe its properties and to evaluate its impact, the use of diversified but, at the same time, specific types of indicators is imposed. For instance, the role of mineralogy on controlling bioavailability of pollutants justifies the search for mineralogical indicators, which must be combined with the classical physical-chemical parameters. This is the case of supergenic mineralogical assemblages, generically named as AMD precipitates. They include hydrated metal-sulphate minerals, which occur as salt efflorescences, and iron-oxyhydroxides, which occur as ochre mixtures, both resulting from the oxidation and hydrolysis of sulphide-rich wastes, in particular iron sulphides, such as pyrite and pyrrhotite (Jambor et al. 2000).

Considering the ecological effects, AMD sites are extreme environments since they impose stress on the majority of organisms, mainly because of acidity and high metal levels. In that way, acidophilic or acid-tolerant organisms can indicate the existence of biological degraded conditions. From a monitoring perspective, some algae, mainly the macroalgal communities, have a great deal of importance. They have optimal growth in acidic conditions, most are mesophilic, and, especially, they are easy to recognize macroscopically. Therefore, although there are inherent problems with spatial and temporal heterogeneity when compared with microalgal community, they can be used as expeditious indicators in analysing systems impacted by AMD (Valente and Leal Gomes 2007). This is the case of Klebsormidium and Euglena genus that are wellknown as metal resistant and have been consistently reported in literature to occur in 
AMD (Brake et al. 2001, Casiot et al. 2004, Nixdorf et al. 2001, Olaveson and Nalewajko 2000, Sabater et al. 2003, Verb and Vis 2001).

Since temporal and spatial variations of AMD are difficult to compare using individual parameters, Gray $(1996,1998)$ proposed an AMD index (AMDI) to evaluate such waters. This quantitative index is calculated using a modified arithmetic weighted index, considering several physical and chemical indicators. However, as stated previously, the database that best describes AMD must contain quantitative data, such as the conventional water composition (ex. $\mathrm{pH}$ and sulphate), which is expressed in concentration units, and qualitative information, like the one related with the ecology and the mineralogy of the impacted systems. In these conditions there is considerable difficulty to model AMD using classical statistical approaches, since the resulted indexes must represent a numeric or descriptive qualification resulting from the integration of very different kind of indicators that are often expressed in non comparable units.

The models based on fuzzy logic come appropriated to deal with the knowledge base that results from the characterization of complex and heterogeneous natural systems, such as AMD. Fuzzy logic allows the incorporation of qualitative information, for instance obtained through field observations, which is better described using natural language (Zadeh 1973, Demicco and Klir 2004).

Considering that fuzzy logic provides powerful tools to capture the perception of natural phenomena it has been applied to a vast number of scientific domains. In geology, fuzzy logic has great potential and several works with broad scope can be cited (Demicco and Klir 2004, Fang and Chen 1990, Fang 1997 and Gedeon 2002). As examples of more specific approaches, Cameron et al. (2001), Mujumdar and Sasikumar (2002), Ratitsch (2000) e Schulz et al. (1999) purpose applications in the areas of geochemistry and 
hydrology. Aroba et al. (2007) have developed a computer tool based on fuzzy logic that allows the interpretation of the AMD process in Tinto and Odiel river estuary. In the present work, a min-max fuzzy inference system (Jang et al. 1997) is specified in order to classify the environmental impact on the riverine system affected by the AMD generated at Valdarcas mining site (Northern Portugal). Previous studies over the period 1999 to 2004 put in evidence the existence of five spatial environments, which can be linked to distinctive contamination degrees (Valente 2004). Given that, the developed approach allows the classification of the water samples in one of these five classes of contamination. The classification procedure is complemented by the determination of a numeric index that reflects the respective contamination degree (AMD index).

\section{Valdarcas mining site}

Valdarcas mine is located in Northern Portugal, in a region where metal mining has a large and long tradition (Fig 1). It was exploited for tungsten in a skarn ore deposit, rich in sulphides, mainly pyrite, pyrrhotite and minus chalcopyrite and sphalerite. The most intensive works took place underground. The mine was closed in the beginning of the eighties and has left about $310000 \mathrm{~m}^{3}$ of sulphide-rich wastes, accumulated in three major impoundments. Marks of environmental impact persist nowadays, mainly due to the discharge of acidic effluents in a small stream (Poço Negro creek). These effluents emerge from the waste-dumps exposed to weathering processes, being the result of mineral-water interactions involving sulphide-rich wastes. Associated complex chain of biotic and abiotic reactions, generating AMD, has been the subject of extensive literature (Kwong and Lawrence 1994, Nordstrom and Southland 1997, Keith and Vaughan 2000). 
At Valdarcas, rainfall is the principal water supply for mineral-water interactions. As far as pluvial regimen is concerned, it is located in the rainiest region of Portugal. Monthly precipitation range from $625 \mathrm{~mm}$ to $1455 \mathrm{~mm}$, values corresponding to the dry semester (from April to September) and to the wet semester (March to October), respectively. Average annual temperature is in the range between 10 and $12^{\circ} \mathrm{C}$.

The acidic seepages and surface runoff from the waste-dumps are naturally conducted to the Poço Negro creek, which represents the main effluent channel, and then discharged in the Coura River. Waste-dumps were built without drainage control, which went far towards the strong physical instability. Consequently, the creek has maintained a very high sediment load that resulted from sulphide-wastes supply. During the period of February and September of 2007, an engineering rehabilitation project was conducted at the waste-dumps, in order to implement measures for erosion control.

\section{Methods}

This section presents the approach used to develop the fuzzy classifier and also includes the analytical procedures carried out to characterize water, alga and mineralogical samples.

Sampling took place monthly over a two-year period (between January 2001 and December 2002). In addition, three single sampling campaigns were performed in February 2005, February 2007 and September 2007. Sampling stations include acidic seepages and surface runoff in the waste-dumps, as well as points along the main effluent channel (Poço Negro creek) (Fig 1). 


\section{Water sampling and chemical analyses}

$\mathrm{pH}$, electric conductivity (EC), redox potential (Eh) and temperature of the water were measured in the field with a multi-parameter meter (Orion, model 1230). The following Orion probes were used: combined pH/ATC electrode Triode ref. 91-07W, conductivity cell DuraProbe ref. 0133030 and a redox combination electrode ORP ref. 96.78.

Laboratory analyses were performed for fluoride and chloride by ion chromatography (IC) with suppressed conductivity detection (761 Compact IC Metrohm). Sulphate was measured by turbidimetry and total acidity by volumetric determination (Standard methods for water analysis reference 4500E and 2310B, respectively). Inductively coupled plasma-atomic emission spectroscopy (ICP-AES) and atomic absorption spectroscopy (AAS) were used for metals. IC, ICP-AES and AAS analyses were preceded by sample filtration through $0.2 \mu \mathrm{m}$ pore-diameter cellulose ester membrane filters. For the analysis of metals, filtration was followed by acidification with $\mathrm{HNO}_{3}$ 65\% suprapur Merck.

\section{Algae sampling and identification}

The algae were always collected at the same time of the day (early in the morning) and observed within $24 \mathrm{~h}$.

Where benthic algae were macroscopically visible, biological material and the sediment on which they grow were collected. If algae were not visible, than effluent filtrates were qualitatively obtained and examined for the presence of suspended cells.

Taxonomic identification was achieved by optical microscopy, based on morphological features and simple coloration tests (amide presence) (Round, 1975). 


\section{Mineralogical sampling and analysis}

Mineralogical composition of the AMD precipitates was analysed by x-ray powder diffraction (XRD) with a Philips X'pert Pro-MPD difractometer, using Cu-Ka radiation. Sample preparation procedures and the appropriated XRD conditions for these kinds of samples, particular leading with low crystallinity and mineral mixtures, are described in Valente (2004). Scanning electron microscopy (on carbon or gold coated samples), with a LEICA S360 microscope, combined with an energy dispersive system (SEM-EDS), allowed the observation of morphological and compositional aspects of the supergenic mineralogical assemblages.

\section{Fuzzy logic - min-max fuzzy inference system}

Fuzzy logic can be summarized as a generalization of the classical set theory that was pioneered by Zadeh (1965). By Zadeh own words, “one of the principal objectives of fuzzy logic is formalization/mechanization of the remarkable human ability to reason and to make decisions in an environment of imprecision, uncertainty, partiality of information and partiality of truth” (Dumitras and Moschytz 2007). Contrary to the classical theory in which sets have crisp boundaries, in fuzzy logic a set has unsharp boundaries. This is an important concept since it better fits almost all real world sets (classes) and therefore is a better approach to model natural phenomena.

A fuzzy set $A$, defined in the universe of discourse $X$, is any set that allows its members $(x \in X)$ to have different grades of membership (membership function $\mu A$ ) in the interval $[0,1]$, equation 1 .

$$
A=\{(x, \mu A(x)) \mid x \in X\}
$$


The membership functions are generally obtained through the parameterization of functions with simple geometric forms such as: Gaussian, PI and Bell functions. As an example of the application of membership functions, Fig. 2 shows the Bell function and a possible fuzzy modelling of an ecological indicator, expressed in a qualitative way, which represents the abundance of the alga Euglena mutabilis. In this context, "abundance of Euglena mutabilis“ is a linguistic or a fuzzy variable. Its representation was obtained adjusting by hand the parameters of the Bell function to best fit the field observations at the five environments that were defined at Valdarcas named as V7, ValdR, V3459, 05A and V216.

The membership function $\mu V 216$ is the one that best captures the meaning of the linguistic expression "very abundant Euglena mutabilis". Therefore, according to this model, a field observation of "very abundant Euglena mutabilis" is attributed to the V216 environment.

A fuzzy classifier is a fuzzy inference system that is based on this type of linguistic variables modulation and on operations on fuzzy sets. It formulates the mapping from a given input to an output, providing the basis from which decisions can be made or classes (patterns) discerned. The classifier developed in the present work is based on a min-max fuzzy inference system (Jang et al. 1997). It has a generalized application and uses the minimum and maximum operations on fuzzy sets.

Fig. 3 exemplifies the application of the min-max fuzzy inference system to classify a pair of variables values $(\mathrm{x}, \mathrm{y})$ into the classes $\mathrm{C} 1$ or $\mathrm{C} 2$. Class $\mathrm{C} 1$ is defined by the pair of fuzzy sets $\{A 1, B 1\}$ whereas class $C 2$ is defined by the pair $\{A 2, B 2\}$. Given the pair (xi,yi) the min-max infers the grade of membership for each class in the following manner: 
- for each value xi and yi, it determines the grade of membership for the fuzzy sets A1, A2 and B1, B2 respectively,

- for each class, C1 and C2, the minimum determines the lowest grade of membership b1 and a2, respectively,

- the maximum operator gives now the highest (b1),

- the pair (xi,yi) is classified as belonging to the class of the highest value, which means that it belongs to the class $\mathrm{C} 1$ with a grade of membership of $\mathrm{b}_{1}$.

The AMD index is obtained through a weighted sum of the min values using a weight factor for each AMD-environment, which reflects the contamination degree.

In fuzzy logic the value of the variables must be in the interval $[0,1]$, which implies a fuzzification procedure dependent on the data format and range.

In the present work the quantitative variables (physical-chemical indicators) were submitted to logarithmic transformation (except the $\mathrm{pH}$ ) followed by a normalization procedure according to equation (2). Subsequently a linear normalization to convert the values to the fuzzy universe was applied.

$$
x_{n}^{\prime}=\frac{x_{n}-\overline{x_{n}}}{\sigma_{x_{n}}}, \mathrm{n} \text { - physical-chemical indicator; } x_{n} \text {-indicator value; } x_{n}^{\prime} \text { - normalized value }
$$

As for the qualitative variables (ecological and mineralogical indicators) the universe of discourse was divided in several fuzzy sets whose purpose is to capture the meaning of the field observations and of the mineralogical analyses. All the indicators were modelled using the Bell function. In the case of ecological and mineralogical indicators the bell function parameters were adjusted manually. Regarding the physical-chemical indicators the parameters were adapted in order to approximate the membership function to the histogram of the respective indicator. 


\section{General properties of the effluent}

The effluent can be described as an acid and rich-sulphate solution with high concentrations of iron, in special Fe(III), calcium, aluminium and manganese. In some samples chemical contamination is enhanced by high levels of arsenic, cooper, zinc and fluoride (raw data in annex). These chemical features constrain the ecological conditions, which results in a structurally simple ecosystem where only acidophilic algae grow. Euglena mutabilis and Klebsormidium sp. are the most well succeeded taxa, presenting the more persistent and densely populated communities.

AMD at Valdarcas leads to the formation of supergenic minerals related to the chemical speciation of iron. In the group of the sulphate salts there are mainly efflorescences of gypsum, rozenite and melanterite. Regarding the ochre precipitates, they form mixtures of iron-oxyhydroxides with variable proportions of jarosite, goethite and schwertmannite. Jarosite occurs abundantly at the surface of the waste-dumps, being progressively replaced downstream, firstly by schwertmannite and then by goethite.

Analytical characterization combined with field observations regarding the ecological and mineralogical properties, has revealed the presence of different patterns with spatial behaviour (Valente 2004, Valente et al 2007). These previous works put in evidence the existence of five AMD-environments that correspond to the grouping of sampling stations (Table I).

\section{Results and discussion}

The database used to develop and evaluate the fuzzy inference system results from the sampling program that was carried out between January 2001 and December 2002. The 
samples colleted in February 2005, February 2007 and September 2007 are used here to demonstrate the fuzzy model application and its effectiveness.

The min-max fuzzy inference system will allow to classify a certain sample in one of the environments (V216, ValdR, 05A, V3459 and V7) and therefore to infer its contamination degree. For that, each environment represents a contamination class, taking in consideration that the extreme conditions are defined by:

- ValdR - class of higher contamination, revealing the proximity to the environmental impact focus (waste-dumps).

- $\quad V 7$ - class of minor contamination, revealing the spacing from the waste-dumps and the prevalence of natural attenuation of the environmental impact.

In order to calculate the AMD index, each environment has been affected by a weight factor that intends to reflect the magnitude of the contamination. To ValdR corresponds the higher weight (0.9), while the lower is attributed to $V 7(0.1)$; environments with intermediate contaminations - 05A, V3459, V216 - have weight factors of 0.3, 0.5 and 0.7 respectively.

The variables used as physical-chemical indicators are the following parameters: $\mathrm{pH}$, EC, Eh, Acidity, $\mathrm{SO}_{4}{ }^{2-}, \mathrm{F}^{-}, \mathrm{Cl}^{-}, \mathrm{Fe}, \mathrm{Mn}, \mathrm{Cu}, \mathrm{Zn}, \mathrm{As}, \mathrm{Ca}, \mathrm{K}, \mathrm{Al}, \mathrm{Na}, \mathrm{SiO}_{2}, \mathrm{Mg}$. The ecological indicators are “abundance of Euglena mutabilis" and “abundance of Klebsormidium sp.”. "Supergenic iron mineral prevailing in the ochre mixtures” and “abundance of sulphate efflorescences” represent the used mineralogical indicators.

Figs. 4, 5 and 6 show the fuzzy bell functions (fuzzy sets) for each AMD-environment, modelling the physical-chemical, ecological and mineralogical indicators, respectively. The analysis of the charts shows the spatial discrimination that corresponds to the AMD-environments in which specific mineral-water interaction phenomena prevails. The following can be summarised: 
- ValdR presents “very low” $\mathrm{pH}$ and "very high” concentration for chemical parameters, except sodium and potassium. Additionally, the modelling of the ecological parameters shows that both algae are "very rare” in this environment, as a consequence of toxic effects promoted by chemical contaminants. Contrarily, sulphate efflorescences are "very abundant” as well as the mineral jarosite ("very strong predominance of jarosite"). These properties are in accordance with the nature of the mineral-water interactions that occur in this environment. In fact, ValdR represents the result of slow water percolation in the interior of the waste-dumps. This allows the dissolution of silica and other chemical species, which are solubilised even from more stable minerals such as the silicates. This is the most oxidant environment and it is easily distinguished, since the generality of the pollutants presents the higher levels. The exceptions noted for sodium and potassium may be related with the strong precipitation of jarosite which retains efficiently these elements. The stability of jarosite relatively to goethite and schwertmannite is insured by the constant supply of acidic effluent from the interior of the waste-dumps and also resulting from the dissolution of the soluble sulphates which occur on the surface.

- V216 presents high dispersion for the physical-chemical parameters, which may reflect the influence of aspects such as fluctuations in the pluvial regimen, runoff conditions and water residence time in the waste-dumps. Therefore it can be seen as a "shock" environment expressing the following conditions with diversified effects: physical instability of the waste-dumps promoting chemical reactivation of the sulphide wastes in the rainiest periods; acidity supply from the interior of waste-dumps; dilution observed in the longest rainy periods. The modelling of the ecological indicators shows a "very high abundance" of 
Euglena mutabilis. and "lower abundance" of Klebsormidium sp. Jarosite dominates the ochre mixtures ("strong predominance of jarosite”). Concerning sulphate efflorescences, V216 presents a high variety of situations (from "very rare” to "very abundant”) in agreement with the influence of diversified geochemical conditions.

- V3459 displays an intermediate behaviour for the generality of the pollutants. Modelling of physical-chemical indicators reflects some dispersion between minimum and maximum values, however less significant than V216. Sulphate efflorescences are "very rare" and schwertmannite is the "most abundant" mineral in the ochre mixtures. Both acidophilic algae are "abundant”. The flatness in the modelling of the Euglena mutabilis indicator reflects the fluctuations in its abundance. These properties can be related to variations in hydraulic, ecological and geochemical conditions observed along the creek. The effect of dilution induces an increase in the $\mathrm{pH}$ values which promotes the instability of jarosite and its replacement for schwertmannite. Also the decrease in the content of the generality of pollutants, comparatively with ValdR, denotes the occurrence of processes of natural attenuation, such as precipitation of oxyhydroxides, metal adsorption and dilution of the acidic effluent.

- $05 A$ environment is well discriminated based on the behaviour of the qualitative indicators, both ecological and mineralogical. Here the Klebsormidium sp. is “very abundant”, being the richer environment concerning this alga. Its presence seems to be favoured by a combination of hydrologic, topographic and mineralogical conditions. This alga establishes mainly in flowing flat shallow water, growing on slightly loosely ferruginous substrates, where schwertmannite is "higher than" jarosite. These are the properties observed at the seepages 
occurring in the upper flat sections of the creek, where large amount of mining wastes are accumulated.

- $\quad$ V7 presents the lowest dispersion for all indicators and in generally the lower level of pollutants. This may correspond to the effect of dilution, which has maximum expression in this environment, and to the attenuation processes that take place in the upstream environments. As a consequence of higher chemical stability, goethite is "higher than" schwertmannite and jarosite is "absent". This mineralogical behaviour, noted in the ochre mixtures, is in agreement with the pH field stability for these minerals (Bigham et al. 1996). Lower contamination, especially in acidity, results in less favourable conditions to support acidophilic algae communities. Therefore Euglena mutabilis is "very rare" and Klebsormidium sp is "rare”. Although rare, Klebsormidium sp. persists better in this more distant environment, since it has a wide tolerance to lower levels of contamination.

\section{Application of the min-max fuzzy inference system}

When applied to a certain sample the min-max fuzzy inference system will respond with the sample classification in one of the AMD-environments, from which it is possible to infer the contamination degree. Table II demonstrates the application of the model to two samples extracted from the database - V603/02 and V902/07.

Given the set of indicators that describes the AMD samples, the fuzzy model starts by determining the grade of membership for the different fuzzy sets. Then, min-max system classifies the samples as belonging to the AMD-environment that presents the maximum value. Therefore V603/02 belongs to the environment V216, with a grade of 
membership of 0.933 , while V902/07 is also well classified, with a grade of membership of 0.853 .

V603/02 presents higher AMD index, reflecting a superior contamination degree due to the position of the respective sampling station at the waste-dumps surface. The AMD index for V902/07, by its turn, reflects already the occurrence of some dilution and other processes of natural attenuation, which is promoted by the distance to the wastedumps.

Table III presents the classification result and the AMD index obtained for the samples collected in February 2005, February 2007 and September 2007. The samples from the campaigns carried out in February 2005 and February 2007 were classified as belonging to the environments in which they were effectively collected. On the contrary, the samples V709/07 and V409/07, colleted in September 2007, were classified as belonging to V3459 and V216 environments, respectively. In fact, in these two cases, the generality of the physical-chemical indicators are rather different from the average for the V7 and V3459 environments. The same happens with the ecological and mineralogical indicators. The presence of acidophilic algae and of the mineral schwertmannite at V7, in September 2007, denotes an increase in the contamination degree due to an extension of the effects of the AMD from the waste-dumps. Such increase is also highlighted in the AMD indexes. This result can be related to the rehabilitation project that took place at Valdarcas site between February and September. By itself, the engineering intervention was a focus of instability, once it has affected the thermodynamic equilibrium that was already established. For instance, the mobilization of the wastes and the movement of vehicles over the dump surfaces may have promoted the destruction of some supergenic mineralogical structures that encapsulate the 
sulphide minerals, protecting them from oxidation. Consequently, metals and acidity were released, creating more severe contamination in the aquatic system.

The absence of an indicator does not make impossible the application of the model. This can be observed in one of the examples presented in table II. Sample V902/07 was well classified even without the Eh indicator. Missing parameters are removed from the model and the classification only fades away regarding those parameters. Nevertheless, it is possible to infer correctly the contamination degree using a restricted number of physical-chemical indicators, specifically the $\mathrm{pH}$, EC, Sulphate, together with the ecological and mineralogical indicators.

\section{Conclusions}

Using a wide database resulting from two years of monthly monitoring, a fuzzy model to classify AMD samples and to infer the contamination degree through the calculus of a numeric index has been developed and evaluated.

The developed approach was based on five distinctive environments, established by means of physical-chemical, ecological and mineralogical data, observed as the creek flows away from the waste-dumps. The application of fuzzy logic had the important advantage, comparatively with the classical modelling approaches, of easily allowing the aggregation of the quantitative and qualitative indicators. In that way, an intuitive field perception, for instance, related with the ecology and mineralogy of the system, can be incorporated in the model in order to better describe AMD and fulfil the characterization that results from numeric data about water quality. Another advantage is that the application of the model is not disabled when some indicators are missing. In that case, the classification procedure only weakens concerning the missing information. 
For future monitoring procedures the model can be used to evaluate the environmental impact related with the spreading of the AMD conditions. For instance, if a sample collected at V3459 or V7 is classified as belonging to a more contaminant environment then, it may be assumed that contamination is extended downstream. This probably will be reflecting instability processes at the waste-dumps, as it was demonstrated using the samples collected during rehabilitation project implemented in 2007. On the other hand, if a sample collected at V3459 is classified as V7, then this can be interpreted as a quality improvement, probably due to natural attenuation processes occurring upstream. The application of the model will also allow an appreciation about temporal evolution of this aquatic system. If future sampling gives a systematic predominance of $V 7$ classifications then the system is revealing a trend of AMD attenuation. Given that the fuzzy model can be applied in a long-term basis, allowing flexible and cost-effective environmental monitoring of Valdarcas mining site. It can also be a useful tool for monitoring purposes in other mining sites with similar AMD conditions.

\section{Acknowledgements}

The authors thank Prof. J. Rino and Prof. A. Calado from research centre - ELMASPortugal for help with algal identification. They are grateful to colleagues Lucia Guise and A. Azevedo for assistance with chemical analysis and DRX analysis, Fernanda Lima for her help with field work and Clara Oliveira for final linguistic corrections. Authors also would like to thank an anonymous reviewer for the valuable comments and suggestions.

\section{References}

Aroba J, Grande JA, Andújar JM, de la Torre ML, Riquelme JC (2007) Application of fuzzy logic and data mining as tools for qualitative interpretation of acid mine processes. Environmental Geology 53:135-145 
Bigham JM, Schwertmann U, Traina SJ, Winland RL, Wolf M. (1996) Schwertmannite and the chemical modeling of iron in acid sulfate waters. Geochimica et Cosmochimica Acta 60: 2111-2121.

Brake SS, Dannelly HK, Connors KA (2001) Controls on the nature and distribution of an alga in coal mine-waste environments and its potential impact on water quality. Environmental Geology 40: 458-469

Cameron E, Peloso GF (2001) An application of fuzzy logic to the assessment of aquifers’ pollution potential. Environmental Geology 40: 1305-1315.

Casiot C, Bruneel O, Personne J, Leblanc M, Elbaz-Poulichet F (2004) Arsenic oxidation and bioaccumulation by the acidophilic protozoan, Euglena mutabilis, in acid mine drainage (Carnoulès, France). Science of The Total Environment 320: 259-267.

Demicco RV, Klir GJ (2004) Fuzzy logic in geology. Elsevier Academic Press, San Diego, 347p.

Dumitras A, Moschytz G (2007) Understanding Fuzzy Logic: An Interview with Lotfi Zadeh [DSP History]. Signal Processing Magazine, IEEE 24:102 - 105

Fang JH, Chen HC (1990) Uncertainties are better handled by fuzzy arithmetic. American Association of Petroleum Geologists Bulletin, 74: 1228-1233.

Fang JH (1997) Fuzzy logic and geology. Geotimes 42 : 23-26.

Gray NF (1996) A substrate classification index for the visual assessment of the impact of acid mine drainage in lotic systems. Water Resources 30: 1551-1554.

Gray NF (1998) Acid mine drainage composition and the implications for its impact on lotic systems. Water Resources 32:2122-2134.

Jang JR, Sun CT, Mizutani E (1997) Neuro-fuzzy and soft computing. Matlab Curriculum Series, Prentice-Hall, Upper Saddle River, 614p.

Jambor JL, Nordstrom DK, Alpers CN (2000) Metal-sulfate salts from sulfide mineral oxidation. In: Alpers CN, Jambor JL, Nordstrom DK (eds) Sulfate minerals: Crystallography, geochemistry and environmental significance. Reviews in Mineralogy and Geochemistry 40: 305-350.

Keith CN, Vaughan DJ (2000) Mechanisms and rates of sulphide oxidation in relation to the problems of acid rock (mine) drainage. In: Campbell LS, Valsami-Jones E, Batchelder M (eds) Environmental Mineralogy: microbial interactions, anthropogenic influences, contaminated land and waste. The Mineralogical Society Series 9: 117-139.

Kwong YT, Lawrence JR (1994) Mineralogical controls of sulfide oxidation. National Hydrology Research Institute, NHRI contribution $n^{\circ} 94010$.

Mujumdar PP, Sasikumar K (2002) A fuzzy risk approach for seasonal water quality management of a river system. Water Resources Research 38: 1-9.

Nixdorf B, Fyson A, Krumbeck H (2001) Review: plant life in extremely acidic waters. Environmental and Experimental Botany 46: 203-211.

Nordstrom DK, Southam G (1997) Geomicrobiology of sulfide mineral oxidation. In: Banfield JF and Nealson KH (eds) Geomicrobiology: interactions between microbes and minerals. Reviews in Mineralogy 35: 361-390.

Olaveson MM, Nalewajko C (2000) Effects of acidity on the growth of two Euglena species. Hydrobiologia 433: 3956.

Ratitsch G (2000) Application of fuzzy clusters to quantify lithological background concentrations in streamsediment geochemistry. Journal of Geochemical Exploration 71: 73-82.

Round F (1975) The biology of the algae. Edward Arnold, London, 278p.

Sabater S, Cambra J, Catalan J, Guasch H, Ivorra N, Romaní A (2003) Structure and function of benthic algal communities in an extremely acid river. Journal of Phycology 39: 481-489.

Schulz K, Huwe B, Peiffer S (1999) Parameter uncertainty in chemical equilibrium calculations using fuzzy set theory. Journal of Hydrology 217: 119-134. 
Valente T, Leal Gomes C (2007) The role of two acidophilic algae as ecological indicators of acid mine drainage sites. Journal of Iberian Geology 33:283-294.

Verb RG, Vis ML (2001) Macroalgal communities from acid mine drainage impacted watershed. Aquatic Botany 71: 93-107.

Zadeh LA (1965) Fuzzy sets. Information and control 83: 338-353.

Zadeh LA (1973) Outline of a new approach to the analysis of complex systems and decision processes. IEEE transaction systems, Man, and Cybernetics, vol. SMC-3:28-44.

Valente T (2004) Modelos de caracterização do impacte ambiental para escombreiras reactivas - equilíbrio e evolução de resíduos de actividade extractiva. PhD. thesis, Universidade do Minho, Portugal [in Portuguese]

\section{Figure Captions}

Fig. 1 Location of Valdarcas mining site in Northern Portugal and sampling stations.

Fig. 2 Bell function (a) and an example of its parameterization for the fuzzy variable "abundance of Euglena mutabilis“ (b).

Fig. 3 Example of the application of the min-max fuzzy inference system.

Fig. 4 Membership functions - fuzzy sets - used in the fuzzy model for physical-chemical indicators. $\mu$ ValdR, $\mu V 216, \mu 05 A, \mu V 3459$ and $\mu V 7$ are bell functions: bell(x; a,b,c), with a=maximum-minimum; $\mathrm{b}=1$; $\mathrm{c}=$ average.

Fig. 5 Membership functions - fuzzy sets - used in the fuzzy model for ecological indicators

Fig. 6 Membership functions - fuzzy sets - used in the fuzzy model for mineralogical indicators 
Table I AMD-environments used in the fuzzy classifier.

\begin{tabular}{ccc}
\hline Sampling stations & Description of the AMD-environment & $\begin{array}{c}\text { Designation of the AMD- } \\
\text { environment }\end{array}$ \\
\hline $\begin{array}{c}\text { \{V1,V2,V6 }\} \\
\{\text { ValdR }\}\end{array}$ & Surface runoff at the waste-dumps \\
$\{05 \mathrm{~A}\}$ & Seepages at the base of the waste-dumps & ValdR \\
$\{\mathrm{V} 3, \mathrm{~V} 4, \mathrm{~V} 5, \mathrm{~V} 9\}$ & Main effluent channel & 05A \\
$\{\mathrm{V} 7\}$ & Discharging point in the Coura river & V3459 \\
\hline
\end{tabular}


Table II Example of the application of the min-max fuzzy inference system.

\begin{tabular}{|c|c|c|c|c|c|c|c|c|c|c|c|c|c|c|}
\hline \multirow[b]{2}{*}{ Indicator } & \multicolumn{2}{|c|}{ Sample V603/02 } & \multicolumn{5}{|c|}{ AMD - Environment } & \multicolumn{2}{|c|}{ Sample V902/07 } & \multicolumn{5}{|c|}{ AMD - Environment } \\
\hline & Raw data & $\begin{array}{l}\text { Fuzzy } \\
\text { Values }\end{array}$ & $\mu_{\mathrm{ValdR}}$ & $\mu_{\mathrm{V} 216}$ & $\mu_{05 \mathrm{~A}}$ & $\mu_{\mathrm{V} 3459}$ & $\mu_{\mathrm{V} 7}$ & Raw data & $\begin{array}{l}\text { Fuzzy } \\
\text { Values }\end{array}$ & $\mu_{\text {ValdR }}$ & $\mu_{\mathrm{V} 216}$ & $\mu_{05 \mathrm{~A}}$ & $\mu_{\mathrm{V} 3459}$ & $\mu_{\mathrm{V} 7}$ \\
\hline $\mathrm{pH}$ & 2.83 & 0.442 & 0.937 & 0.965 & 0.639 & 0.960 & 0.940 & 2.95 & 0.512 & 0.885 & 0.990 & 0.762 & 0.999 & 0.982 \\
\hline $\mathrm{EC}(\mu \mathrm{S} / \mathrm{cm})$ & 883 & 0.367 & 0.611 & 0.989 & 0.976 & 0.911 & 0.999 & 1486 & 0.494 & 0.773 & 0.999 & 0.788 & 1.000 & 0.637 \\
\hline Eh $(\mathrm{mV})$ & 486 & 0.836 & 0.993 & 0.974 & 0.966 & 0.999 & 0.943 & - & & & & & & \\
\hline $\mathrm{SO}_{4}{ }^{2-}(\mathrm{mg} / \mathrm{L})$ & 222 & 0.323 & 0.549 & 0.973 & 0.985 & 0.818 & 0.887 & 779 & 0.509 & 0.787 & 0.999 & 0.861 & 1.000 & 0.562 \\
\hline $\begin{array}{l}\text { Acidity (mg/L } \\
\left.\qquad \mathrm{CaCO}_{3}\right)\end{array}$ & 215 & 0.353 & 0.309 & 0.983 & 0.996 & 0.868 & 0.997 & 635 & 0.541 & 0.551 & 0.997 & 0.788 & 0.998 & 0.636 \\
\hline $\mathrm{Fe}(\mathrm{mg} / \mathrm{L})$ & 39.4 & 0.387 & 0.670 & 0.987 & 0.980 & 0.937 & 0.997 & 149 & 0.524 & 0.854 & 0.998 & 0.839 & 0.999 & 0.878 \\
\hline Mn (mg/L) & 1.24 & 0.028 & 0.800 & 0.933 & 0.499 & 0.630 & 0.275 & 14.9 & 0.349 & 0.985 & 0.859 & 0.923 & 0.999 & 0.654 \\
\hline $\mathrm{Cu}(\mathrm{mg} / \mathrm{L})$ & 1.27 & 0.524 & 0.581 & 0.988 & 0.707 & 0.746 & 0.147 & 0.27 & 0.327 & 0.337 & 0.982 & 0.951 & 0.975 & 0.409 \\
\hline Zn (mg/L) & 0.16 & 0.269 & 0.658 & 0.997 & 0.975 & 0.919 & 0.786 & 0.50 & 0.417 & 0.815 & 0.975 & 0.954 & 0.996 & 0.331 \\
\hline As (mg/L) & 0.086 & 0.287 & 0.806 & 0.999 & 0.948 & 0.899 & 0.748 & 0.0063 & 0.000 & 0.578 & 0.875 & 0.927 & 0.987 & 0.991 \\
\hline $\mathrm{Ca}(\mathrm{mg} / \mathrm{L})$ & 15.0 & 0.300 & 0.461 & 0.959 & 0.792 & 0.699 & 0.728 & 83.4 & 0.607 & 0.871 & 0.978 & 0.743 & 0.987 & 0.470 \\
\hline K (mg/L) & 1.00 & 0.000 & 0.986 & 0.948 & 0.976 & 0.794 & 0.925 & 1.82 & 0.290 & 0.937 & 0.997 & 0.847 & 0.979 & 0.860 \\
\hline $\mathrm{Al}(\mathrm{mg} / \mathrm{L})$ & 6.86 & 0.181 & 0.762 & 0.989 & 0.926 & 0.819 & 0.488 & 39.3 & 0.345 & 0.913 & 0.963 & 0.871 & 0.993 & 0.543 \\
\hline $\mathrm{Na}(\mathrm{mg} / \mathrm{L})$ & 2.51 & 0.519 & 0.994 & 0.999 & 0.765 & 0.906 & 0.124 & 7.85 & 0.859 & 0.770 & 0.911 & 0.913 & 0.992 & 0.493 \\
\hline $\mathrm{SiO}_{2}(\mathrm{mg} / \mathrm{L})$ & 7.94 & 0.348 & 0.610 & 0.997 & 0.800 & 0.869 & 0.250 & 33.9 & 0.731 & 0.994 & 0.899 & 0.904 & 0.993 & 0.482 \\
\hline $\mathrm{Mg}(\mathrm{mg} / \mathrm{L})$ & 1.74 & 0.224 & 0.535 & 0.992 & 0.911 & 0.829 & 0.068 & 11.3 & 0.576 & 0.906 & 0.895 & 0.749 & 0.989 & 0.097 \\
\hline $\mathrm{F}^{-}(\mathrm{mg} / \mathrm{L})$ & 4.10 & 0.350 & 0.590 & 0.998 & 1.000 & 0.949 & 0.997 & 3.10 & 0.316 & 0.551 & 0.992 & 0.993 & 0.911 & 0.891 \\
\hline $\mathrm{Cl}^{-}(\mathrm{mg} / \mathrm{L})$ & 4.98 & 0.675 & 0.980 & 1.000 & 0.963 & 0.984 & 0.674 & 11.0 & 0.943 & 0.957 & 0.913 & 0.892 & 0.961 & 0.606 \\
\hline AEM & $\begin{array}{c}\text { Very } \\
\text { Abundant }\end{array}$ & 0.95 & 0.000 & 0.997 & 0.044 & 0.880 & 0.000 & $\begin{array}{c}\text { Near } \\
\text { abundant }\end{array}$ & 0.650 & 0.000 & 0.424 & 0.445 & 0.941 & 0.000 \\
\hline AK & Rare & 0.254 & 0.000 & 1.000 & 0.137 & 0.305 & 0.171 & Abundant & 0.850 & 0.000 & 0.012 & 0.800 & 0.853 & 0.000 \\
\hline SIM & $\begin{array}{c}\text { Jarosite+ } \\
\text { Sch. }\end{array}$ & 0.174 & 0.903 & 1.000 & 0.672 & 0.371 & 0.001 & Sch. & 0.550 & 0.009 & 0.059 & 0.500 & 1.000 & 0.029 \\
\hline ASE & $\begin{array}{l}\text { Midpoint } \\
\text { abundance }\end{array}$ & 0.481 & 0.500 & 1.000 & 0.000 & 0.000 & 0.000 & $\begin{array}{l}\text { Very } \\
\text { Rare }\end{array}$ & 0.000 & 0.015 & 0.500 & 1.000 & 1.000 & 1.000 \\
\hline Minimum & & & 0.000 & 0.933 & 0.000 & 0.000 & 0.000 & & & 0.000 & 0.012 & 0.445 & 0.853 & 0.000 \\
\hline Maximum & & & & 0.933 & & & & & & & & & 0.853 & \\
\hline Classification & & & & V216 & & & & & & & & & V3459 & \\
\hline AMD Index & & & & 0.65 & & & & & & & & & 0.57 & \\
\hline
\end{tabular}

AEM - Abundance of Euglena mutabilis; AK - Abundance of Klebsormidium sp.; SIM - Supergenic iron mineral prevailing in ochre mixtures; ASE - Abundance of sulphate efflorescences;

Sch - Schwertmannite; “_“ indicator not determined. 
Table III Results of the fuzzy inference system for the 2005 and 2007 sampling campaigns.

\begin{tabular}{ccc}
\hline Sample & $\begin{array}{c}\text { Classification } \\
\text { (AMD-Environment) }\end{array}$ & $\begin{array}{c}\text { AMD } \\
\text { Index }\end{array}$ \\
\hline V402/05 & V3459 & 0.50 \\
V902/05 & V3459 & 0.56 \\
V702/05 & V7 & 0.07 \\
ValdR02/07 & ValdR & 0.75 \\
V402/07 & V3459 & 0.53 \\
V902/07 & V3459 & 0.57 \\
V702/07 & V7 & 0.05 \\
V409/07 & V216 & 0.67 \\
V909/07 & V3459 & 0.20 \\
V709/07 & V3459 & 0.35 \\
\hline
\end{tabular}

